\title{
Dispositivo De Calibração De Trena E Régua Graduada
}

\section{Calibration Device Measuring Tape And Ruler Graduate}

Fernando Felippe Moura da Gama Santos¹, Kleber Luiz da Silva², Luciano Galdino³

\begin{abstract}
1.Fernando Felippe Moura da Gama Santos: Graduado em Tecnologia em Mecatrônica Industrial e graduando em Engenharia Mecatrônica pela faculdade Eniac. Email: fernandofelippemoura@hotmail.com.

2.Kleber Luiz da Silva Graduando em Engenharia Mecatrônica pela faculdade Eniac. Email: kleluiz@hotmail.com.

3.Luciano Galdino Professor de Física e Elementos de Máquina na Faculdade ENIAC. Mestre em Ciências Exatas e da Terra na área de Física Nuclear pela USP, especializado em Física pela USP e Licenciado em Matemática pela UNG. E-mail: lucianogaldino1@yahoo.com.br.
\end{abstract}

\section{Resumo}

Este artigo apresenta detalhadamente os conceitos técnicos e normas necessárias para a automatização do sistema de calibração de trena e régua graduada, e também a obtenção de conceitos para sistemas de transmissão vertical realizado por motor DC e sistema de controle (controlador lógico programável) e suas características técnicas, instrumentos de medição como micrômetro, trena e suas grandezas, normas de calibração e metrologia, além da montagem da estrutura do dispositivo, especificação do tipo de material utilizado e suas medidas e também os dados necessários para a certificação de calibração (nome, especificações técnicas, materiais utilizados, modelo de equipamento, temperatura ...).

Palavras-Chave: Calibração. Trena. Régua.

\begin{abstract}
This article details the technical concepts and rules necessary for the automation of tape calibration system and graduated ruler, and also obtaining concepts for vertical transmission systems performed by DC motor and control system (PLC) and their characteristics techniques, such as measuring instruments micrometer, and their magnitudes tape, metrology calibration and standards addition to mounting the device structure, speciffing the type of material used and their measurements and also the data required for calibration certification (name, specifications techniques, materials used, equipment model, temperature... ).
\end{abstract}

Keywords: Calibration, Measuring tape, Ruler. 


\section{Introdução}

A metrologia é uma ciência de medição onde é derivada de forma rigorosa por ensaios e períodos de medições. Esse tipo de ciência se apoia no que se pode ouvir e ver, não sendo formada através de idéias ou pensamentos pessoais. Através desta forma de se constituir onde é um tipo de ciência confiável onde se comprova todo e qualquer conhecimento teórico devido ter sido testado e comprovado fisicamente. Um fator importante quando é falado de medição é saber o que será medido, como por exemplo: tempo, temperatura, grandezas específicas, comprimento de uma barra, resistência elétrica de um fio entre outros.

O dispositivo padrão de calibração para régua e trenas graduadas, tem por objetivo realizar medições lineares. A régua graduada baseia-se em uma lâmina de aço carbono onde se tem gravado as medidas em grandezas como centímetro $(\mathrm{cm})$ e milímetro (mm); A trena é um instrumento de medição formado por uma fita de aço ou tecido, graduada em uma ou em ambas as faces, no sistema métrico e/ou no sistema inglês, ao longo de seu comprimento, com traços transversais. Com base nas duas características dos dispositivos de medições será realizada a automação desse dispositivo de calibração para trenas e réguas graduadas; a automação será realizada utilizando dispositivos mecânicos e eletrônicos, onde faz com que ajude o contexto de medição facilitando o colaborador realizar a calibração nesse sistema e trazendo a segurança e principalmente a economia de tempo e dinheiro.

Devido esses pontos positivos que a automação traz, alavancou nos últimos anos o aumento do mercado no ramo de componentes eletrônicos e mecânicos com o intuito de facilitar a automação trazendo mais confiabilidade; em consequência trouxe o baixo custo dos componentes fazendo com que a automação deste dispositivo seja viável financeiramente. Sendo abordado assunto sobre as áreas de mecânica, informática e a eletrônica e seus dispositivos como controlador lógico programável (CLP), sensores e motores DC.

Todos os resultados obtidos na calibração serão anotados em documentos, e os resultados podem ser coletados através de um software, (como o Word ou Excel). Este documento servirá como guia para a calibração e posterior execução do certificado final, sendo que no término do certificado deve haver informações relevantes, como endereço do cliente, dados do instrumento a ser calibrado e informações dos resultados acionados com as incertezas da medição, essas 
incertezas são denominadas através de estudos estáticos para o instrumento a ser calibrado.

\section{Instrumentos De Medição}

É um dispositivo para realizar medições, individualmente ou associado a um ou mais dispositivos suplementares (Kobayoshi, 2012). O controle de um processo produtivo só pode ser significativo, se forem utilizados instrumentos de medição com garantia de exatidão, caso estes instrumentos não estiverem devidamente calibrados podem haver um desvio um uma variação sistemática. Para um instrumento de medição ser utilizado ele deve garantir alguns requisitos:

Exatidão - É a aptidão do instrumento para dar indicações próximas do verdadeiro valor da grandeza medida;

Estabilidade - É a capacidade do instrumento de medição para conservar as suas características metrológicas;

Repetitividade - É a capacidade do instrumento de medição para dar, em condições de utilização definidas, as respostas muito próximas quando se aplica repetidamente o mesmo sinal de entrada;
Reprodutibilidade - É a comparação entre resultados das medições de uma mesma grandeza por diversos indivíduos verificando a variação em diversas condições tais como: métodos de medição; operador; instrumento de medida; local; condições de utilização; tempo.

No âmbito da Metrologia Legal, os instrumentos de medição são utilizados no comércio, nas áreas de saúde, segurança e meio ambiente e na definição ou aplicação de penalidades (efeito fiscal).

\subsection{Régua graduada.}

Segundo ABNT-NBR 10038 (1987) A régua graduada ou escala é um instrumento de aço inox, tendo sua graduação situada em suas extremidades, composto de marcações equidistantes, normalmente com gravações em milímetro ou polegada ou ainda com as duas unidades, cuja faixa de medição pode variar de 0 até $2000 \mathrm{~mm}$ (figura 1).

Normalmente é um instrumento utilizado na medição de dimensões lineares, quando não há necessidade de grande precisão. Podemos encontrar no mercado alguns tipos de régua graduada, tais como: régua sem encosto, régua com encosto, régua com encosto interno, régua de profundidade e régua de dois encostos. 
Figura 1: Escala Superior e Inferior

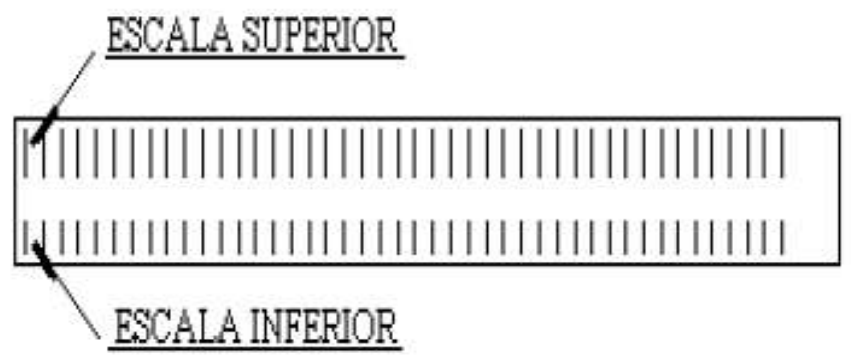

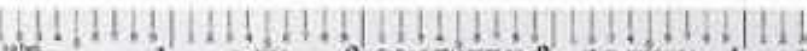

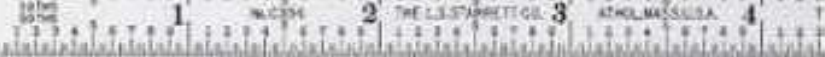

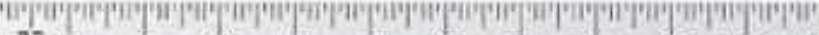

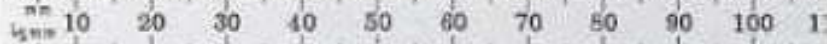

Fonte: Dados da empresa EMPTEQ. Site de domínio público em 2014.

\subsection{Trena}

Conforme ABNT-NBR 10123 (2012) A trena é um instrumento de medição cujo sua fita é graduada no sistema métrico ao longo do seu comprimento, com traços transversais e sobreposta a um suporte dotado de um mecanismo de recolhimento manual ou automático da fita e possuindo um sistema de trava (Figura 2).

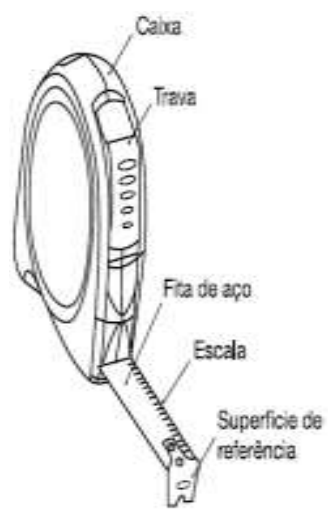

Figura 2: TIPOS DE TRENAS

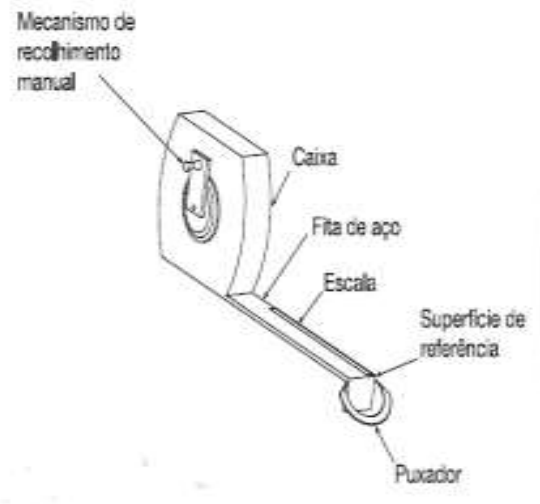

Fonte: ABNT (2014).

É um instrumento de medida usada para medir distâncias. Pode designar uma fita flexível e graduada que se utiliza para medir tecidos, ou determinados tipos de fitas métricas retrácteis que consistem numa fita de metal, plástico ou fibra de vidro enrolada num invólucro. No Brasil, as trenas retráteis e feitas de metal são também chamadas "fita métrica". As unidades de medidas das trenas são: centímetros, milímetros, polegadas e pés.

Geralmente este tipo de instrumento de medição é utilizado em medições internas ou externas ou de grandes áreas. As de diâmetro servem para calcular o revestimento de pilares que terão acabamento arredondado. 


\subsection{Micrômetro}

O micrômetro é um instrumento metrológico capaz de aferir as dimensões lineares de um objeto (tais como espessura, altura, largura, profundidade, diâmetro etc.) com precisão da ordem de micrometros, que são a milionésima parte do metro $(0,001 \mathrm{~mm})$. Têm vasta aplicação na indústria mecânica, principalmente naquelas que fabricam peças ou componentes que requer precisões milésimas, tais como: indústria automotiva, aviação, equipamentos hospitalares, etc. $\mathrm{O}$ micrômetro funciona por um parafuso micrométrico e funciona por deslizamento de uma haste sobre uma peça dentada e permite a leitura da espessura por meio de um nônio ou de um mecanismo semelhante ao de um relógio analógico.

Segundo (FERES, 2014) "Jean Louis Palmer apresentou, pela primeira vez, um micrômetro para requerer sua patente. $\mathrm{O}$ instrumento permitia a leitura de centésimos de milímetros, de maneira simples". Ao passar dos anos foram feitas melhorias e fez com que o micrômetro se torna-se mais preciso que o paquímetro. A figura 3 apresenta os principais componentes de um micrômetro e o quadro 1 indica as características e/ou funções de cada componente.

Figura 3: Componentes de um micrômetro.

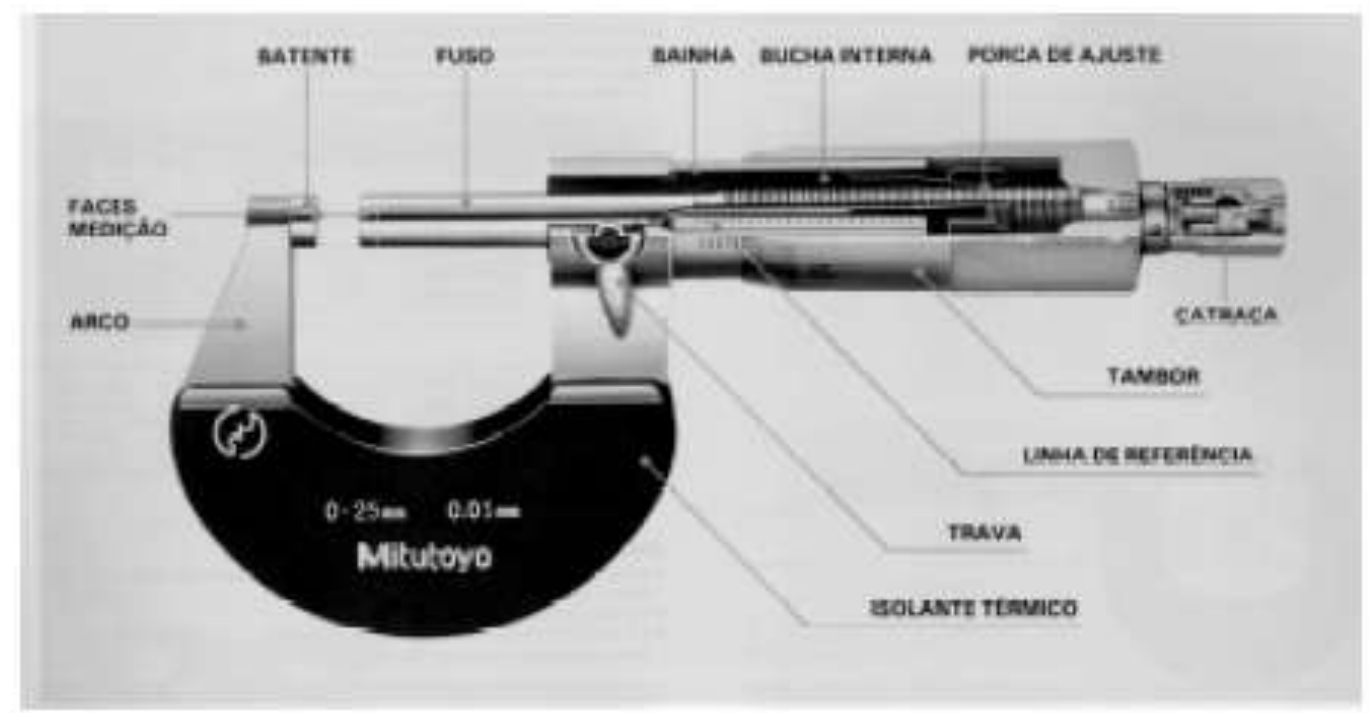

Fonte: ETEC (2014) 


\begin{tabular}{|l|l|}
\multicolumn{2}{l}{ Quadro1 - Características de cada componente do micrômetro } \\
\hline COMPONENTE & FUNÇÃO \\
\hline Arco & $\begin{array}{l}\text { É constituído de aço especial ou fundido, cuidado termicamente para tirar } \\
\text { tensões interna. }\end{array}$ \\
\hline Isolante Térmico & $\begin{array}{l}\text { Fixado ao arco, evita a dilatação devido isolar a transferência de calor das } \\
\text { mãos para o instrumento }\end{array}$ \\
\hline Fuso Micrométrico & $\begin{array}{l}\text { Constituído de aço especial temperado e retificado para garantir exatidão } \\
\text { na rosca }\end{array}$ \\
\hline Faces de Medição & $\begin{array}{l}\text { Encosta na peça a ser medida, devido isso apresenta rugosidade nas faces. } \\
\text { Em alguns instrumentos, esses contatos são feitos de matérias mais duro } \\
\text { de alta resistência devido o desgaste. }\end{array}$ \\
\hline Porca de Ajuste & Faz o ajuste da folga do fuso micrométrico. \\
\hline Tambor & $\begin{array}{l}\text { Onde se encontra a escala centesimal. Funciona da basicamente da seguinte } \\
\text { forma com cada volta, seu deslocamento é equivalente ao passo do fuso } \\
\text { micrométrico. }\end{array}$ \\
\hline Catraca & Serve para ajudar na pressão de medição constante. \\
\hline Trava & Imobiliza o fuso numa medida predeterminada. \\
\hline
\end{tabular}

Fonte: Elaborado pelos autores nos laboratórios da Faculdade de Tecnologia Eniac 2014.

Os micrômetros possuem três características principais: capacidade, resolução e 2. Incerteza E Calibração aplicações. Segundo Feres (2014), para verificar se o micrômetro com capacidade de $25 \mathrm{~mm}$ está calibrado devem-se encostar as faces dos contatos e verificar se a borda do tambor iguala ao traço zero da bainha, conforme figura 4 .

Figura 4: Forma de leitura do micrômetro

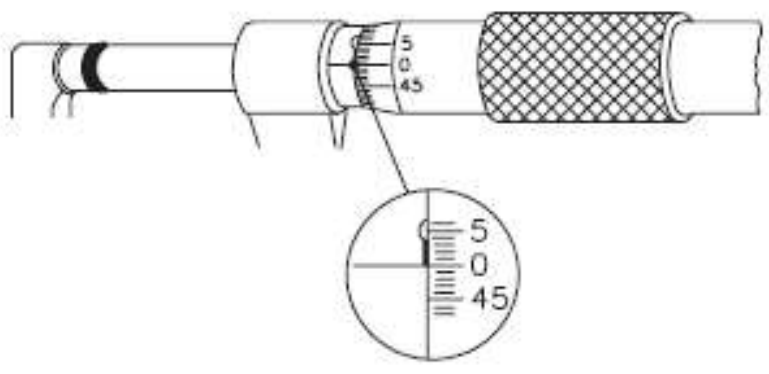

Fonte: Feres (2014). incerteza de medição é o parâmetro associado ao resultado de uma medição, que caracteriza a dispersão dos valores que podem ser razoavelmente atribuídos ao mensurado. $\mathrm{Na}$ norma ISO 9001 (ABNT, 1994), o requisito 4.11, cujo título é "Controle de equipamentos de inspeção, medição e ensaios", mostra vários aspectos metrológicos, sempre dando uma relevância maior ao fato de que todos os equipamentos que sejam de suma importância para garantia da qualidade do produto fabricado devem ser calibrados periodicamente, e a incerteza de medição deve ser conhecida e divulgada. 
Para garantir se a incerteza foi determinada corretamente e o instrumento apto a ser utilizado, deve-se seguir o fluxo como é demonstrado na figura 5 .

A Figura 5demonstra o Fluxograma para Cálculo de Incerteza

Figura 5: Fluxograma para Cálculo de Incerteza

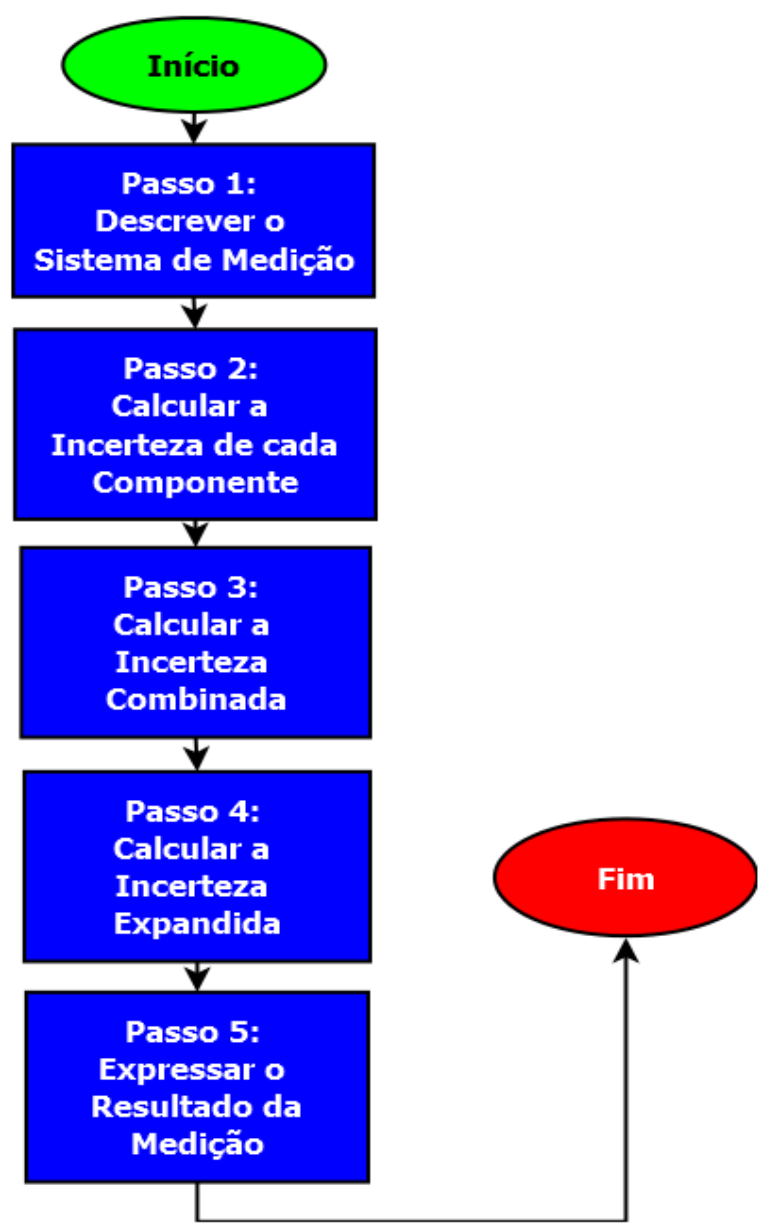

Fonte: Elaborado pelos autores nos laboratórios da Faculdade de Tecnologia Eniac 2014.

3. Dispositivo Automatizado Para A Calibração De Trena E Régua.
O projeto estabelecido trata-se de um dispositivo de calibração de trenas e régua graduada, tendo por objetivo melhorar o processo de calibração, seguindo normas e conceitos da ABNT (Associação Brasileira de Normas Técnicas) e RBC (Rede Brasileira de Calibração). Este dispositivo de medição foi projetado com a finalidade de determinar o erro de indicação existente em trenas e réguas graduadas que são utilizadas em processos produtivos em geral, principalmente os processos ligados as áreas de estamparia, perfilados, etc. Peças e/ou equipamentos de grandes dimensões são dimensionados através destes instrumentos (trenas e réguas) e muitas vezes as tolerâncias são apertadas e a única forma de assegurar que estas dimensões estão dentro da tolerância requerida em seus processos é se conhecer os erros que estes instrumentos de medição possuem, com esse objetivo, foi projetado o dispositivo de calibração. Estes instrumentos sofrem desgastes com o tempo de utilização e para que se tenha certeza que o mesmo está adequado para uso e dentro das suas tolerâncias deve ser checado junto a um padrão de referência. Estes padrões devem ser calibrados pelo INMETRO, ou por laboratórios credenciados, que abrange na rede $\mathrm{RBC}$ (Rede Brasileira de Calibração).

$\mathrm{Na}$ calibração da trena, devem ser checados os erros de indicação durante o deslocamento do inicio ao fim da escala, a 
espessura do encosto e folga do encosto, ou seja, segundo a norma NBR ABNT-10123 (Instrumento de Medição e Controle), o erro de indicação da trena de fita de aço é feito da seguinte forma: sobre um plano horizontal de referência coloca-se a fita a ser calibrada tracionada adequadamente e a ela justapor uma régua ou trena padrão (Figura 9). Com auxílio de um microscópio, ou lupa graduada, comparam-se as diferenças entre as indicações.

Figura 9: Dispositivo de calibração

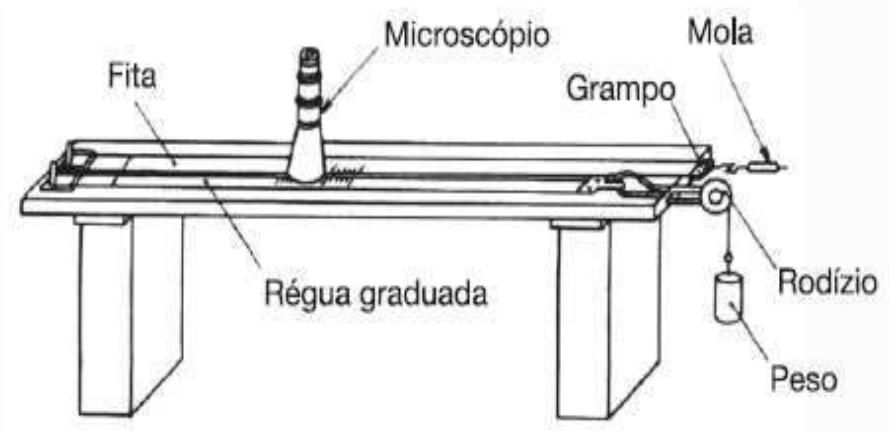

Fonte: ABNT (2014)

Já na régua graduada deve ser checado o deslocamento do início ao fim da escala, o instrumento deve ser sobreposto ao dispositivo de calibração e alinhado, com intuído de não haver erro de paralaxe, sendo assim, a calibração tem um processo parecido com o da trena, diferenciando somente os itens a serem checados, que no caso da régua será só o deslocamento.

Com base nesta norma foi criado o dispositivo de calibração de trenas e régua graduada, no qual foi construído com o intuito de atender os requisitos adequados para realizar a calibração.

\subsection{Plano horizontal}

O plano horizontal do dispositivo (figura 10) foi construído com dois perfis de alumínio Hyspex 74300, com aproximadamente $3000 \mathrm{~mm}$ de comprimento (figura 11), acoplado sobre uma bancada, com uma régua padrão de $2000 \mathrm{~mm}$ fixado a esta base.

\section{Figura 10 - Dispositivo de Calibração de Trena e Régua Graduada}

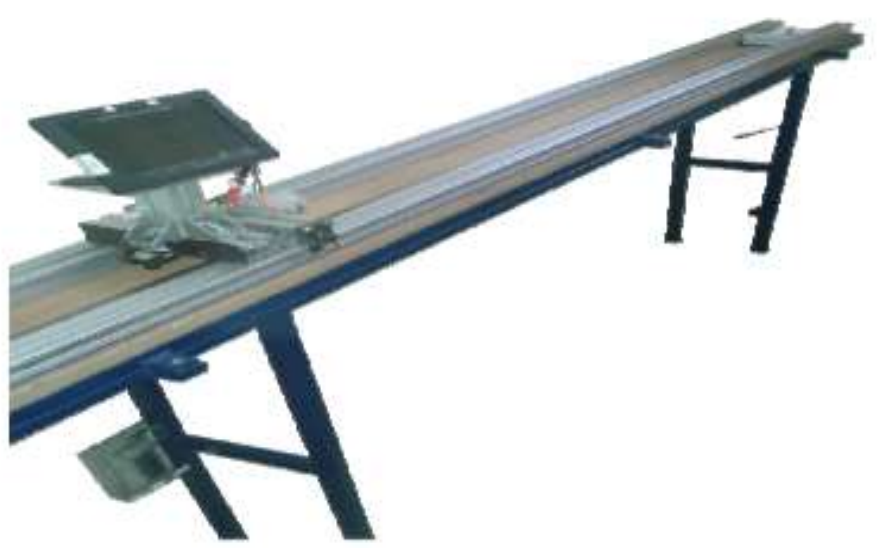

Fonte: Dados de domínio público da empresa EMPTEQ

A escolha deste perfil foi em virtude da alta facilidade de aplicação com os itens compostos no projeto, além de ser um material leve, de fácil manuseio, resiste à oxidação e intempéries. 
Figura 11 - Vista Superior Perfil Hyspex 74300 (dimensões em mm)

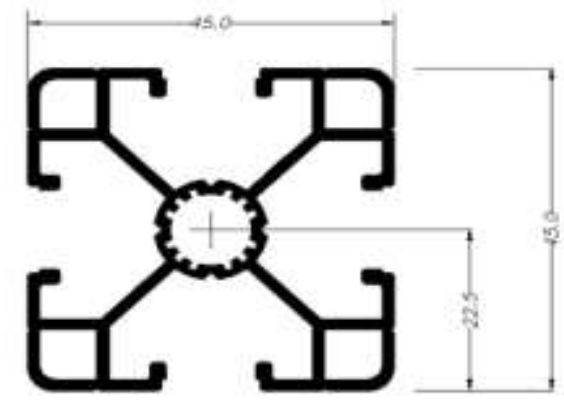

Fonte: Página de domínio público da empresa Hyspex.

\subsection{Base para visualização e deslocamento}

Para visualização do erro de indicação foi criado uma base com o mesmo perfil mencionado anteriormente. Nesta base na forma de mancal, encontra-se uma tela de LCD (Figura 12) de alta definição, junto com um micro câmera e duas guias fixando a outra parte do perfil. No centro da peça há uma guia acoplada a um tambor micrométrico, com a finalidade de poder visualizar o erro de indicação em milésimo de milímetro (1 micrometro), conforme figura 13.
Figura 12 - Estrutura com tela

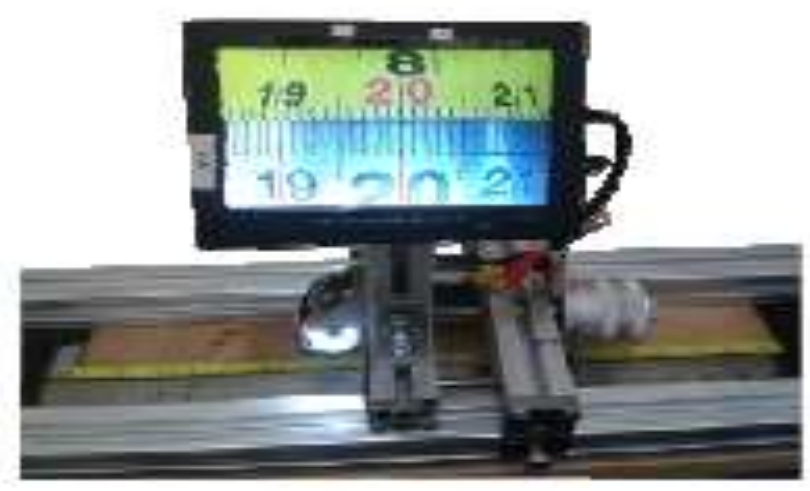

Fonte: Dados da empresa EMPTEQ

Figura 13 - Tambor Micrométrico

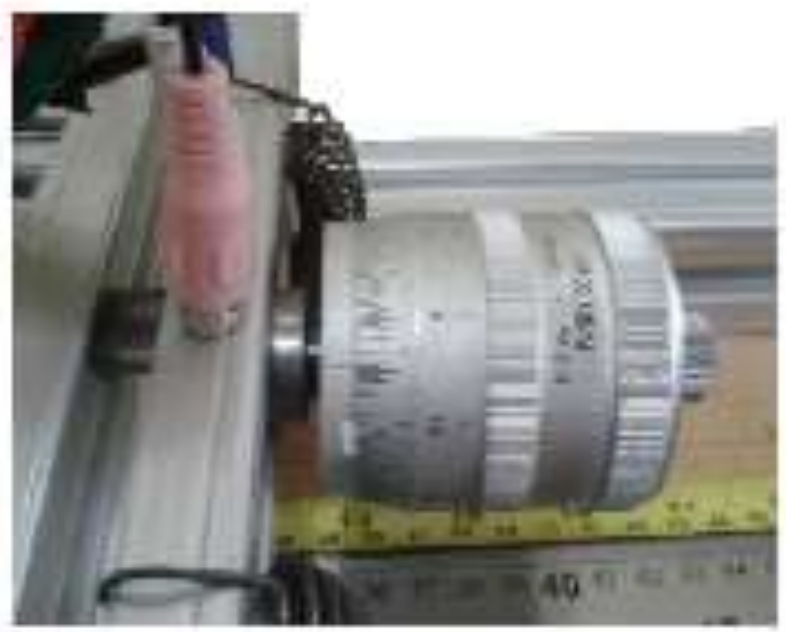

Fonte: Dados de domínio público da empresa EMPTEQ
4. Dispositivos utilizados na automação

Todo projeto de automação deve prever a utilização de vários dispositivos elétricos, mecânicos e computacionais para dar suporte aos trabalhos que o sistema deverá executar. A seguir 
são apresentados os elementos que serão utilizados nesse projeto.

\subsection{Sistema de transmissão: motores e polias de acionamento}

Segundo Pucci (2014) o acionamento para o deslocamento pode ser realizado através de um motor DC e de um sistema de polias com correias. Neste motor será fixada uma polia no seu eixo, o qual irá trabalhar junto com outra polia fixa, utilizando para isso uma correia (figura 6).

Figura 6: Transmissão e acionamento por polias.

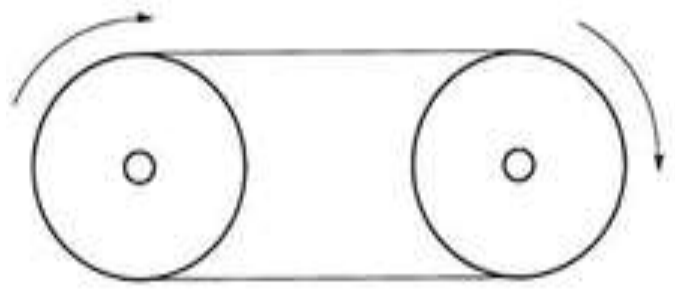

Fonte: Pucci (2014).

\subsection{Controlador lógico programável (CLP).}

O deslocamento da base é feito automaticamente através de um motor DC, com transmissões de polia, correia e o acionamento feito através de um CLP modelo Encolder 74-173, fabricante Mitutoyo (figura 7), com isso, a base se desloca no plano horizontal, onde há 5 (cinco) sensores ópticos acoplador, posicionados em pontos estratégicos, o qual irá referenciar cinco pontos de medição.

Figura 7 - CLP modelo Encolder 74-173

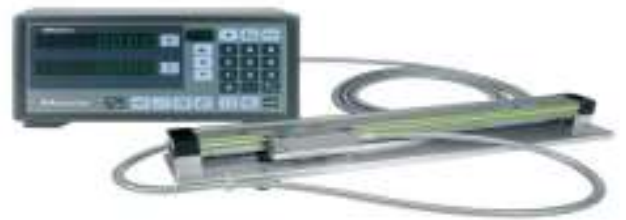

Fonte: Página da empresa Mitutoyo.

O encolder fica posicionado na parte inferior da base horizontal do dispositivo para que não haja nenhum risco de atrito com a base, sensores ou quaisquer estruturas do dispositivo que se encontra na parte superior.

\subsection{Sensor óptico PHCT202}

Os sensores que compõem o projeto são do tipo óptico infravermelho modelo PHCT202, conforme a figura 8. É um sensor fácil de encontrar em qualquer loja de eletrônica. A escolha deste sensor ocorreu devido a alguns fatores, como facilidade de instalação, por possuir um circuito simples e ser um componente com facilidade de trocar caso houver necessidade. Seu funcionamento ocorre quando o dispositivo que envolve o uso da luz como meio de transmissão passa sobre o óptico com um LED emissor e um elemento invólucro hermétrico que não pode receber luz externa. 
Como descrito no tópico anterior o mesmo foi posicionado em 5 (cinco) pontos estratégicos, ou seja, de acordo com as normas de calibração (ABNT-NBR 10123 e ABNT-NBR 10038) onde indicam que é necessário distribuir 10 (dez) pontos de acordo com a faixa de medição do instrumento, porém não foi posto 10 (dez) sensores pelo fato do dispositivo não possuir um comprimento elevado, e com dimensionamento que possui hoje, ficaria inviável, mas a norma também estabelece a opção de fazer incremento durante as medições, ou seja para trenas e réguas com faixa de medição superior à 2 (dois) metros, a medição será efetuada por etapa, respeitando-se o comprimento útil máximo do padrão, sendo que a trena deverá ser reposicionada a partir de 2 (dois) metros, somando-se a leitura (segunda leitura) obtida no padrão.

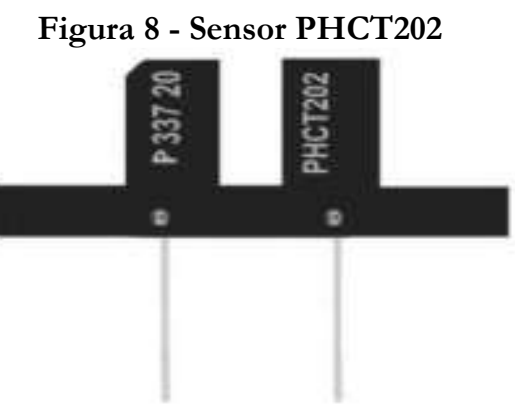

Fonte: Página de domínio público da empresa Photonic.

\section{Resultados Da Calibração}

Os resultados das medições durante a calibração ficam armazenados no CLP, porém não há um software que grave essas informações, sendo assim, o técnico que está fazendo o trabalho deve ir a umas das funções do CLP e colher os dados e transferir para uma planilha no Excel. Todos os resultados obtidos na calibração devem ser anotados num documento chamado "Registro de Medições”. Este documento servirá como guia para a calibração e posterior execução do certificado final. As orientações para a elaboração e o preenchimento do Registro de Medições são apresentadas em um procedimento operacional adotado pelo laboratório de calibração.

\subsection{Incerteza da medição}

A forma de cálculo e suas equações são apresentadas por um registro determinado pelo laboratório e seus cálculos são realizados através de uma planilha eletrônica validada, no entanto, na realização de qualquer calibração, são feitos estudos do instrumento a ser calibrado, para determinar quais fontes de incerteza que interferem na calibração do mesmo, com isso é possível realizar os cálculos estatísticos para determinar o valor final da medição.

No caso da trena, referente ao seu processo de calibração e determinação do erro de indicação, temos as fontes de incerteza indicadas no quadro 2: 
Quadro 2 - Incerteza de medição da trena

\begin{tabular}{|l|c|c|c|}
\hline \multicolumn{1}{|c|}{ Fonte } & Tipo & \multicolumn{2}{c|}{ Distribuição } \\
\hline Incerteza devido à repetitividade & A & Normal & 1 \\
\hline $\begin{array}{l}\text { Incerteza proveniente do certificado de } \\
\text { calibração do padrão utilizado }\end{array}$ & B & Normal & $\mathrm{k}$ \\
\hline Incert. do padrão (Cab. Microm.) & B & Normal & $\mathrm{k}$ \\
\hline Resolução do instrumento & B & Retan. & $\sqrt{3}$ \\
\hline Resolução do padrão & B & Retan. & $\sqrt{3}$ \\
\hline Influência da Temperatura & B & Retan. & $\sqrt{3}$ \\
\hline Inc. do Coefic. Expansão Térmica & B & Retan. & $\sqrt{3}$ \\
\hline Inc. devido a coincidência de traço & B & Retan. & $\sqrt{3}$ \\
\hline Inc. da curva de calibração do padrão & B & Retan. & $\sqrt{3}$ \\
\hline
\end{tabular}

Fonte: Dados de domínio público da empresa EMPTEQ

$\mathrm{Na}$ calibração de régua graduada as fontes de incerteza são basicamente iguais as da trena, por usar o mesmo dispositivo para realizar as medições, mudando apenas alguns métodos, com isso. O quadro 3 apresenta as fontes de incerteza.

Quadro 3 - Incerteza de medição da trena

\begin{tabular}{|l|c|c|c|}
\hline \multicolumn{1}{|c|}{ Fonte } & Tipo & \multicolumn{2}{c|}{ Distribuição } \\
\hline Incerteza devido à repetitividade & A & Normal & 1 \\
\hline $\begin{array}{l}\text { Incerteza proveniente do certificado de } \\
\text { calibração do padrão utilizado }\end{array}$ & B & Normal & $\mathrm{k}$ \\
\hline Resolução do instrumento & B & Retan. & $\sqrt{3}$ \\
\hline Resolução do padrão & B & Retan. & $\sqrt{3}$ \\
\hline Influência da Temperatura & B & Retan. & $\sqrt{3}$ \\
\hline Inc. do Coefic. Expansão Térmica & B & Retan. & $\sqrt{3}$ \\
\hline Inc. da curva de calibração do padrão & B & Retan. & $\sqrt{3}$ \\
\hline
\end{tabular}

Fonte: Dados de domínio público da empresa EMPTEQ

De acordo com Fidélis (2010), a incerteza do tipo A está relacionado à medida de confiabilidade da medição através da análise das flutuações estatísticas. A incerteza está relacionada ao conceito de desvio padrão, que mede o quanto os dados obtidos variam em relação à média dos próprios dados (isso prova que a incerteza não depende do valor verdadeiro). Já a incerteza do tipo B, depende de quaisquer outros fatores além da aleatoriedade, tais como a maturidade, a intuição e o conhecimento que o experimentador tem acumulado sobre seus instrumentos e 
procedimentos de medição. Vale destacar que avaliações do tipo A e do tipo B, quando executadas corretamente, são igualmente confiáveis na determinação da incerteza de uma medição.

De modo que se tenha o dispositivo de calibração de trena e/ou régua de acordo com os critérios exigidos por norma, o laboratório deve seguir um procedimento de calibração, conhecer bem o instrumento e forma de manuseio. Este procedimento tem o objetivo de descrever o processo de calibração de acordo com o instrumento que irá ser verificado. O quadro 4 indica os documentos que devem ser seguidos num processo de calibração:

Quadro 4 - Documentos utilizados para a execução de uma calibração.

\begin{tabular}{|l|l|}
\hline NOMENCLATURA & DESCRIÇÃO \\
\hline ABNT-NBR 6125 & $\begin{array}{l}\text { Temperatura de referência para medições industriais de dimensões } \\
\text { lineares. }\end{array}$ \\
\hline VIM & $\begin{array}{l}\text { Vocabulário Internacional de Termos e Fundamentais e Gerais de } \\
\text { Metrologia. }\end{array}$ \\
\hline ABNT-NBR 10123 & Trenas e fita de aços. \\
\hline ABNT-NBR 10038 & Régua graduada de aço \\
\hline
\end{tabular}

Fonte: Elaborado pelos autores nos laboratórios da Faculdade de Tecnologia Eniac 2014.

\section{Considerações Finais}

O projeto propôs a automatização de um determinado tipo de dispositivo, utilizando novas tecnologias e equipamentos, com o intuito de buscar melhorias e diminuir o trabalho braçal, sendo assim, seguindo esta base de proposta, foi pensado na automatização de um dispositivo bastante utilizado no nosso dia a dia, o dispositivo de calibração de trenas régua graduada.

O processo de calibração vinha a ocorrer algumas falhas devido a não precisão de medição, sendo que isso para um laboratório não é viável, além disso, não estava atendendo 100\% à norma ABNT-NBR 10123, ou seja, para creditar este tipo de serviço o laboratório deve seguir a risca o que é pedido na norma, devido a essas falhas foi proposto um processo de melhoria, no qual foi aprovado pela empresa.

A automação do dispositivo teve um grande aumento na melhoria do processo de calibração, tendo em vista que o dispositivo antes de ser automatizado, vinha a tomar um grande tempo do técnico que realizava a execução das calibrações, ou seja, a criação do dispositivo automatizado alavancou grandes vantagens em relação a tempo, dinheiro e qualidade de serviço, pois uma calibração que antes vinha a levar aproximadamente 1 (uma) hora e 30 (trinta) 
minutos, passou a ser realizada em 30 (trinta) minutos, sendo assim passou a ter maiores lucros, pois a demanda de serviço desse tipo de calibração teve aumento. Além disso, obteve um alto nível de precisão, com a implantação de instrumentos de leitura mais precisos, no qual foi adequado ao projeto como o fuso micrométrico e a tela LCD de alta definição, sendo assim o erro de indicação que antes era visto em decimo de milímetro passou a ser visto em milésimo de milímetro, além disso, o manuseio que antes era feito manualmente, passou a ser automático, tendo o técnico então o trabalho de somente programar os pontos que serão checados.

Pode-se afirmar que o projeto foi viável a empresa, afinal o investimento para execução do mesmo foi de baixo custo, comparando com o lucro que passou a ter neste determinado tipo de serviço.

\section{Referências}

\section{ASSOCIAÇÃO BRASILEIRA DE NORMAS} TÉCNICAS. ISO 9001: informação e

documentação: citações em documentos:

apresentação. Rio de Janeiro, 1994. Disponível em: <http://www.abnt.org.br> acesso em 20 de abril 2014.

ASSOCIAÇÃO BRASILEIRA DE NORMAS TÉCNICAS. NBR 10123: informação e documentação: citações em documentos: apresentação. Rio de Janeiro, 2004. Disponível em: <http://www.abnt.org.br/cb04/admin/Proj Rev NBR 10123.pdf> acesso em 02 de abril 2014.

ETEC, Apostila Curso Técnico em Mecânica.

Disponível em:

http://engenhariamecanica-

sp.blogspot.com.br/2009/11/apostila-cursotecnico-em-mecanica-etec.html Acesso em 05 de abril de 2014

FERES, A. Micrômetro e Trena. Disponível em: <http://www.albertoferes.com.br/menu_esquer do/downloads/mecanica/Metrologia\%20A11.pd f $>$ acesso em 02 de abril 2014.

FIDÉLIS, Gilberto Carlos. Guia Prático -

Incerteza de medição para iniciantes, Florianópolis, SC, 2010 - Editora CECT. HYSPEX, Perfis de alumínio para Estrutural de Automação. Disponível em : http://www.hyspex.com.br/v2/index.php/perfis -de-alumínio/automacao-industrial/estrutural-deautomacao.html Acesso em 12 de abril de 2014. KOBAYOSHI, Marcelo. (Ed.). Calibração de Instrumentos de Medição: area mecânica dimensional. 2012 1ª Edição - Editora SenaiSP.

MITUTOYO, Escalas de Medição Linear. Disponível em :

<http://www.mitutoyo.com.br/site/produtos/m edicaolinear.html> Acesso em 02 de abril 2014 PHOTONIC, Sensor PHCT202. Disponível em: <http://www.photonics.com> Acesso em 10 de março de 2014. 
PUCCI, L. Movimento e Frequência.

Disponível em: <educação.uol.com.br/física/polias-e-

engrenagens.jhtm> Acesso em 02 abril de 2014. 